\title{
Individual Differences in Acute Responses to MDMA in Humans: Effects of Sex and Past Ecstasy Use
}

\author{
G. Bedi ${ }^{*}{ }^{1,2}$ and H. de Wit ${ }^{1}$ \\ ${ }^{I}$ Department of Psychiatry and Behavioral Neuroscience, University of Chicago, Chicago, USA \\ ${ }^{2}$ Division on Substance Abuse, New York State Psychiatric Institute \& Department of Psychiatry, College of Physicians \\ and Surgeons of Columbia University, New York, USA
}

Keywords: MDMA, ecstasy, mood, cognition, gender.

\section{INTRODUCTION}

Little is known about factors affecting individual differences in acute response to \pm 3 , 4-methlyenedioxymethamphetamine (MDMA; 'ecstasy'). To our knowledge, only one prior report has documented such differences in humans after controlled MDMA administration [1]. In that report, females had greater hallucinogenic and negative psychological responses to MDMA, whereas males showed greater cardiovascular responses. Here, we assessed sex differences in acute subjective and cardiovascular responses to MDMA $(0.75 \mathrm{mg} / \mathrm{kg} ; 1.5 \mathrm{mg} / \mathrm{kg})$. In addition, because animal studies indicate that prior MDMA exposure produces lasting reductions in behavioral responses to the drug [2], we also examined effects of cumulative lifetime ecstasy use on acute MDMA effects.

\section{METHODS}

Data from two within-subjects, placebo-controlled, double-blind, randomized studies conducted from 2007-09 were included. One study $(N=10)$ was an fMRI investigation of MDMA $(0.75 \mathrm{mg} / \mathrm{kg} ; 1.5 \mathrm{mg} / \mathrm{kg})$ effects on social processing [3]. The second $(N=25)$ examined the effects of MDMA $(0.75 \mathrm{mg} / \mathrm{kg} ; \quad 1.5 \mathrm{mg} / \mathrm{kg})$ and methamphetamine $(20 \mathrm{mg})$ on social cognition. Data from MDMA $(0.75 \mathrm{mg} / \mathrm{kg} ; 1.5 \mathrm{mg} / \mathrm{kg})$ and placebo (PBO) sessions were included. Sex differences in peak change scores were assessed using ANCOVAs, with peak change for placebo sessions included as a covariate as necessary. Relationships between lifetime cumulative ecstasy use and peak change in response to MDMA were assessed using Pearson's correlations or partial correlations when peak change on placebo was a significant covariate. Subjective outcome measures were the Drug Effects Questionnaire [4], Visual Analog Scales measuring mood [5], and the Profile of Mood States [6]. Cardiovascular measures were heart rate and blood pressure.

\section{RESULTS}

Combined data comprised healthy males $(N=21)$ and females $(N=14)$ who had used ecstasy at least twice.

\footnotetext{
*Address correspondence to this author at the Department of Psychiatry and Behavioral Neuroscience, University of Chicago, Chicago, USA; Tel: +1 212543 5875; Fax: + 122543 6018; E-mail: gb2326@columbia.edu
}

Participants were 24.5 (S.D. $=4.2$ ) years old, with lifetime ecstasy use on 27.1 (S.D. $=54.1$ ) occasions. Overall, MDMA $(0.75 \mathrm{mg} / \mathrm{kg}, 1.5 \mathrm{mg} / \mathrm{kg})$ dose-dependently increased ratings of feeling any drug effect, feeling high, wanting more drug, stimulation, and anxiety. MDMA $(1.5 \mathrm{mg} / \mathrm{kg}$ only) increased sociability, friendliness, elation, and positive mood, vigor, and nausea ratings. MDMA $(0.75 \mathrm{mg} / \mathrm{kg}$ only $)$ increased confusion relative to PBO. Expected orderly increases in systolic and diastolic blood pressure and heart rate were observed. Effects of MDMA on self-reported stimulation and anxiety, as well as heart rate and diastolic blood pressure, were greater in females than males (Fig. 1). Females also showed greater decreases in self-rated elation and positive mood after MDMA $(0.75 \mathrm{mg} / \mathrm{kg}$ only $)$ than males. Females did not report higher positive mood effects of MDMA than males. Lifetime ecstasy use was not related to any measures assessed.

\section{DISCUSSION}

This analysis supports an earlier report that women may be particularly vulnerable to acute negative subjective effects of MDMA [1], even when doses are matched for body weight. Findings are also consistent with reports that women experience more acute negative effects of recreational ecstasy $[7,8]$ and with animal studies demonstrating that the behavioral effects of MDMA are greater in females [9]. Contrary to the findings of Liechti et al. [1], we found that females also exhibited greater cardiovascular responses to the drug than males. Although inconsistent with the earlier report [1], this finding is consistent with the current female subjects' ratings of heightened stimulation and anxiety after MDMA. Contrary to animal findings, we found no effect of prior ecstasy use on drug responses. However, few heavy users participated; blunted acute responding may be detectable in users with heavier cumulative use.

\section{CONCLUSIONS}

Females appear more vulnerable to acute negative mood and cardiovascular effects of MDMA than males. These findings have implications for recreational and therapeutic MDMA use. Further research is required to better characterize and assess the mechanisms of these differences, including investigation of the influence of menstrual cycle and hormone levels on acute responding to MDMA [see 10]. 

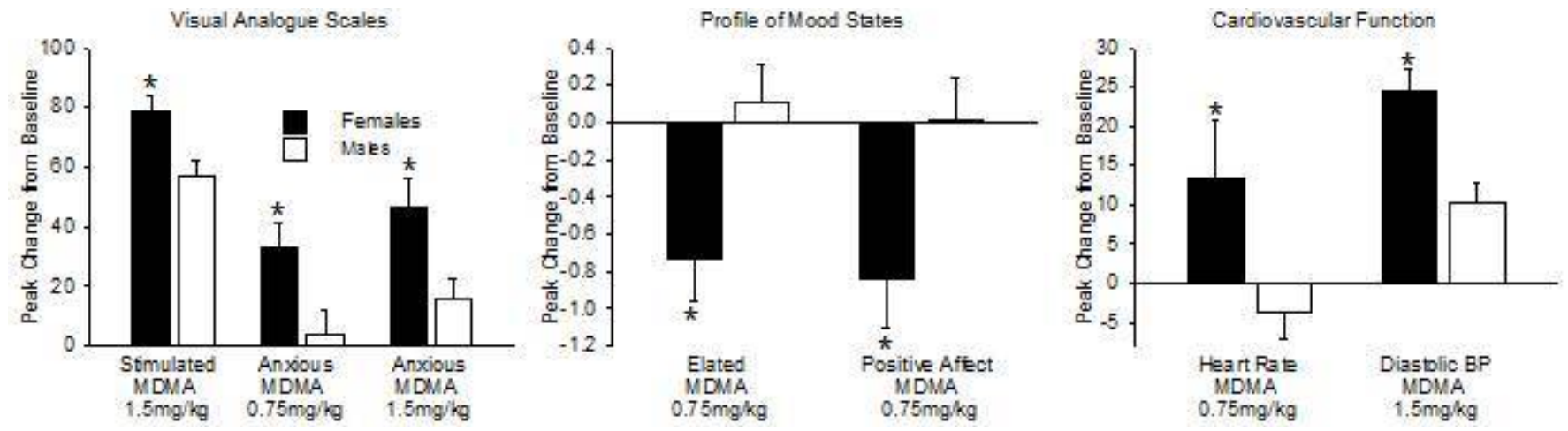

Fig. (1). Sex differences in subjective and cardiovascular MDMA responses. $*=$ Different from males, $p<0.05$.

\section{FUNDING}

NIDA DA026570, NIDA DA02812

\section{DECLARATION OF CONFLICTS}

The authors have no conflicts to declare.

\section{REFERENCES}

[1] Liechti ME, Gamma A, Vollenweider FX. Gender differences in the subjective effects of MDMA. Psychopharmacology 2001; 154: $161-8$.

[2] Thompson MR, Callaghan PD, Hunt GE, McGregor IS. Reduced sensitivity to MDMA-induced facilitation of social behavior in MDMA pre-exposed rats. Prog Neuropsychopharmacol Biol Psychiatry 2008; 32: 1013-21.

[3] Bedi G, Phan KL, Angstadt M, de Wit, H. Effects of MDMA on sociability and neural response to social threat and social reward. Psychopharmacology 2009; 207: 73-83.
[4] Johanson C, Uhlenhuth E. Drug preference and mood in humans: Diazepam. Psychopharmacology 1980; 71: 269-73.

[5] Folstein MF, Luria R. Reliability, validity, and clinical application of the Visual Analogue Mood Scale. Psychol Med 1973; 3: 479-86.

[6] McNair DLM, Droppleman L. Profile of Mood States. San Diego: educational and industrial testing service 1971.

[7] Baylen CA, Rosenberg H. A review of the acute subjective effects of MDMA/ecstasy. Addiction 2006; 101: 933-47.

[8] Topp L, Hando J, Degenhardt L, Dillon P, Roche A, Solowij N. Ecstasy use in Australia: patterns of use and associated harm. Drug Alcohol Depend 1999; 55: 105-15.

[9] Palenicek P, Votava M, Bubenikova V, Horacek J. Increased sensitivity to the acute effects of MDMA ("ecstasy") in female rats. Physiol Behav 2005; 86: 546-53.

[10] Evans SM, Foltin RW. Does the response to cocaine differ as a function of sex or hormonal status in human and non-human primates? Horm Behav 2010; 58: 13-21.

(C) Bedi and de Wit.; Licensee Bentham Open.

This is an open access article licensed under the terms of the Creative Commons Attribution Non-Commercial License (http://creativecommons.org/licenses/ by-nc/3.0/) which permits unrestricted, non-commercial use, distribution and reproduction in any medium, provided the work is properly cited. 